\title{
The Relationships between Social Class, Listening Test Anxiety and Test Scores
}

\author{
Omid Talebi Rezaabadi \\ University of Deakin, Australia \\ E-mail: omidreza1365@yahoo.com
}

Doi:10.7575/aiac.alls.v.7n.5p.147

URL: http://dx.doi.org/10.7575/aiac.alls.v.7n.5p.147
Received: $13 / 06 / 2016$

Accepted: 17/08/2016

\begin{abstract}
This study investigated the relationships between the social anxiety, social class and listening-test anxiety of students learning English as a foreign language. The aims of the study were to examine the relationship between listening-test anxiety and listening-test performance. The data were collected using an adapted Foreign Language Listening Anxiety Scale and a newly developed Foreign Language Social Anxiety Scale. The potential correlation between social anxiety and listening-test performance was investigated by the correlation coefficient $\mathrm{r}_{\mathrm{xy}}$. A moderate positive correlation was found between students' social class and social anxiety. The results suggest that pedagogical methods suggested to lessen this anxiety were effective. There was also a clear relationship between social anxiety, listening-test anxiety and listening performance. This exploratory research has several pedagogical implications.
\end{abstract}

Keywords: anxiety, Foreign language (FL) learning, listening, sociolinguistics, Social class

\section{Introduction}

Listening is the basis of language learning, without which no interaction between speakers can take place. Foreignlanguage (FL) students must develop listening skills to communicate in real-life contexts. Learners' social anxiety may affect their FL listening performance. Social anxiety is defined by the American Psychiatric Association (2000) as the severe fear of contravening social norms. Some researchers have explained the subtle connections between culture and social anxiety in terms of the cross-cultural psychopathological characteristics of social anxiety (Draguns \& TanakaMatsumi, 2003). A common feature of social anxiety is the fear of receiving negative feedback from others. Accordingly, social anxiety is associated with social norms and role expectations, which are related to culture and social class. Social class has far received little attention in education, which is a gap that has been recently highlighted in the field of applied linguistics (Darnon, Dompnier \& Poortvliet, 2012; Jury, Smeding, Court \& Darnon, 2015). As noted by Grant (2001), political and social scientists define social class as the outcome of orthodox social-stratification models that categorise individuals into an array of hierarchical social categories. "Social class is understood to be embedded in social relations and as emergent in day-to-day activities, even if there is an objective reality of institutions and larger social structures and forces which shape the prospects of individuals acting within them" (Block \& Corona, 2014, p. 34). It determines, and is determined by, professional and educational/academic hierarchies within a given culture (Gracia, 2015).

The role of anxiety in listening apprehension is receiving increasing attention from educational practitioners and researchers alike (Young, 1999). Numerous studies have been conducted on FL anxiety in relation to listening and speaking skills, and their findings suggest that oral classroom activities cause the greatest uncertainty and anxiety among language learners (Price, 1991). According to MacIntyre and Gardner (1994), students suffering from FL anxiety are tense and apprehensive, especially when participating in listening and speaking activities in the second language. Students with greater FL anxiety tend to experience greater listening anxiety (Hussein, 2005). In addition, Hussein (2005) found both FL listening anxiety and FL learning anxiety to correlate negatively with listeningcomprehension scores and final marks, such that students with greater listening and learning anxiety performed less well overall. Scarcella and Oxford (1992) found that listening anxiety has debilitating effects on students who encounter difficult or insufficiently explained tasks. The findings of some studies have shown that language anxiety is likely to be negatively associated with students' performance in oral tests (Phillips, 1992; Young, 1986). However, although emphasis has been placed on the debilitating effects of anxiety on listening skills, Brown (2007) and Putwain (2008) have noted that a certain degree of anxiety is helpful for language learners.

If an individual is told that he/she will not succeed, he/she is indeed less likely to do so. Regardless of their potential, many FL learners in lower social classes, especially those who are uneducated or impoverished, are subjected to this kind of negative reinforcement, which is ultimately self-fulfilling. The aim of this study is to fill a gap in the research by investigating the correlation between social anxiety and FL listening anxiety. The main goals of the study are to provide both teachers and language learners with clearer insights into the nature of EFL listening anxiety and its detrimental 
effects on FL students, and to characterise the relationship between FL learners' listening anxiety and the social anxiety that arises from their social-class status.

\section{Literature review}

\section{1 Social Classification}

Research on social stratification has accelerated recently (Mare, 2014). The term social classification, also called as social stratification, is obscure. For example, it may signify either the dissociation of a population into social classes or a socially biased process of classification. The term social class, also known as class, originated from the Latin classis and is used to categorize individuals by wealth (Brown 2009). Its meaning depends on the branch of the social sciences in which it is used. Sociologists have defined social classification as the sorting of people by profession, which gives lawyers, doctors and professors a higher status than, for example, unskilled labourers. Macionis and Gerber (2010) defined social stratification as a system by which society categorizes the rank of people in a hierarchy. It classifies individuals according to their relative socio-economic positions (Barker, 1955). This reinforces a broad set of economic, political, social and ideological inequalities, because socio-economic distinctions tend to reflect existing hierarchies of rank, status and privilege. Social classes are often divided into three broad categories: the upper classes, which comprise the richest and most influential people in society; the middle classes, which consist of ordinary people such as academics and managers; and the lower classes, made up of people who lack the bare necessities of life. However, a special classification was used in this study, which is discussed in the procedure section.

\subsection{Test-taking Anxiety and Listening-Comprehension Anxiety}

Researchers have paid particular attention to the related concept of FL listening test anxiety. No consensus has yet been reached on the effects of listening-test anxiety on language learners. The results of most studies in this area have indicated that listening comprehension test performance is negatively related to listening anxiety (Elkhafaifi, 2005; Mills, Pajares \& Herron, 2006). Kim (2000) discovered a negative relationship between FL listening anxiety and learning among Korean EFL students. FL learners' degree of listening proficiency also affects their anxiety levels (Mills, Pajares \& Herron, 2006). In'nami (2006) found listening-test anxiety and listening performance to be unrelated. His results indicated that none of the three key causes of test anxiety - general test apprehension, thoughts unrelated to the test and emotional state - influenced listening-test marks. In'nami (2006) thus attributed poor performance in listening tests to other factors, such as the importance of test results and test-takers' English listening proficiency, previous experience of tests and confidence in their use of strategies to control anxiety. Shomoossi and Kassaian (2009) investigated the influence of test anxiety on listening and speaking skills, and found no significant difference in students' anxiety levels before and after a listening test.

In light of the above findings, the following hypotheses were proposed (with a 0.05 significance level).

$\mathrm{H}_{1}$. Students from unsociable social classes experience more FL social anxiety than students from sociable social classes with the same level of language proficiency.

$\mathrm{H}_{2}$. There is a positive relationship between the students listening anxiety and their social anxiety treatment.

$\mathrm{H}_{3}$. There is a negative relationship between EFL learners' listening-test anxiety and listening performance.

\section{Methodology}

3.1 Participants

Seventy-eight intermediate English learners were selected from 179 Test of English as a Foreign Language (TOEFL) candidates to participate in an academic IELTS listening course at an English institute in Iran. The students were aged between 16 and 28, with an average age of 22. Thirty-five of the students were from sociable social classes and fortythree were from unsociable social classes. The female to male ratio was 49 to 29 ; the majority of the participants were female.

\subsection{Instruments}

Data were collected using the IELTS listening tests developed by the University of Cambridge, a version of the FLLAS (Elkhafaifi, 2005) (see Appendix A), the Foreign Language Social Anxiety Scale (FLSAS) (see Appendix B) and an open-ended questionnaire (see Appendix C). The IELTS listening tests were used to evaluate the listening performance of students with various levels of anxiety. The FLLAS measures the degree to which a person experiences stress when listening to an FL. It is comprised of 30 questions, all of which are answered on a 5-point Likert scale ranging from 'strongly disagree' to 'strongly agree'. The FLSAS, which comprises 21 items, measures the social anxiety experienced by an FL learner when learning an FL. The FLSAS items are rated by participants on the same Likert scale as the FLLAS items.

Factor analysis was carried out to investigate the underlying variables of FLLAS and the FLSAS. Those items which their KMO measures were less than .5 for these two tests, were omitted. The terms of lack of sampling adequacy and multi-collinearity were fulfilled. Accordingly, the sample size was sufficient for factor analysis. The correlation matrix carried out to investigate the underlying structure of instruments did not have a multi-collinearity problem, thus, excessively high correlations between all of the items. The FLLAS and the FLSAS were proven to be reliable and valid, with alpha coefficients of 0.61 and 0.59 in this study. The open-ended questionnaire comprised three general questions about the students' FL listening anxiety, in relation to two social categories: sociable social class and unsociable social class, designed to reflect their own voices. 


\subsection{Procedure}

In this study, the following two-part social class classification is adopted. This classification system, developed by a doctoral sociology student named XXXX, is based on the results of a 2014 survey conducted in Iran and data on the social status of the participants in this study. It should be noted that this classification system cannot be assumed to be representative of all families in Iran, as the country's population is vast. As there could be some overlap between these two following social classes, each participant was also interviewed in person to make sure he/she was placed into the right class.

1. 'Sociable' social classes: doctors, specialists, managers, professors, teachers, miners, social workers, etc.

2. 'Unsociable' social classes: servants, drivers, barbers, farmers, peasants, freelancers, grocers, etc.

The 78 participants were interviewed individually to facilitate their categorisation into these two social categories. A teacher divided the students equally, in accordance with their social class, into two advanced English IELTS listening classes. The two sets of students had the same teacher, from whom they received two 90-minute sessions of English instruction per week for 24 weeks, in accordance with an Academic IELTS Listening Course. The research was conducted at a well-known English institute in Iran. Midway through the course, the EFL students were asked to complete the FLLAS and the FLSAS to gain insight into their levels of FL listening anxiety and FL social anxiety. They were also requested to complete an open-ended anxiety questionnaire, which enabled them to provide their own explanations for their listening anxiety. Subsequently, the teacher began to use certain social-anxiety techniques to deal with the students' illogical social reactions to EFL listening tests. In the last 2 weeks of the course, the students were again asked to fill in the FLLAS and the FLSAS to measure their anxiety levels after receiving the social-anxiety treatment. In the last week of the course, the students took their final academic listening test. The data gathered were used to explore the effects of the social-anxiety treatment on learners' FL social anxiety, and also to characterise the relationships between learners' listening anxiety and social anxiety, listening-test anxiety and listening performance. The most important advice and techniques given by the teacher on dealing with social anxiety was as follows.

1. Everybody has experienced social anxiety, which can be dealt with easily by understanding some key features of anxiety.

2. It is normal to experience social anxiety.

3. Anxiety is a normal physiological response to danger or other challenges, which triggers an increase in blood to our muscles, making us stronger.

4. Anxiety is something that we create when there is no real reason for concern or fear.

5. Understanding the causes of your social anxiety helps you to manage it. The following strategies can be used: a. take notes on the reasons for your anxiety in different social situations; and b. take notes on all of your physical and psychological reactions to social anxiety.

6. Once you have identified the causes of your social anxiety, try to determine whether your negative thoughts are based on facts or imagination. Ask yourself questions such as the following: 'Did the negative or embarrassing thing that I was anxious about actually happen?' This may help you to realise that social anxiety is often illogical.

7. Whenever you experience social anxiety, try to calm down using the following strategies: a. take deep and regular breaths to lessen the speed of your abnormal breathing; and b. alternately tighten and relax your muscles, as this helps to calm your nerves.

8. Try to do your best and accept that you are fallible.

9. Face the music. Actively seek out potentially embarrassing situations, because repeated encounters with such situations may help you to become comfortable with them.

10. Finally, keep the following adages in mind: 'to want to is to be able to' and 'practice makes perfect'.

The most important IELTS listening strategies suggested by the teacher were as follows.

1. Concentrate on listening to help you work out what the speaker wants to say.

2. Do not worry if you do not understand a word, as the word may not be essential to the overall sense.

3. If you are taking too long to answer a question, make a guess and move on quickly to save time.

4. If you find the question too difficult, do not panic; instead, relax and attempt to think creatively.

5. Try to write, read and listen at the same time.

6. Answer all of the questions, for two reasons: 1. the IELTS test does not incur penalties for wrong answers; and 2. it is easy to confuse blank spaces on your answer sheet when you return to unanswered questions.

7. Check your answers.

8. Read the instructions, questions and answers before the recording begins.

9. Try to be aware of the context of each speaker: where is he/she located, and what is his/her purpose in speaking? 
10. Predict the speaker's next words by paying attention to 'signpost' words and phrases such as 'consequently', 'on the contrary' and 'in other words'.

11. Section 3 of the IELTS listening test often comprises a dialogue relating to education; make sure that you are well prepared for this section by learning vocabulary relevant to education.

12. There is a lot of reading to do in Section 4; prepare for this section by making sure that you do not fall behind the speakers.

13. Consider at least two questions at the same time to ensure that if you fall behind in one question, you do not miss the next.

14. Take shorthand notes in your question booklet to save time, as you will have an opportunity at the end of the test to transfer your answers to the answer sheet.

15. As questions usually follow the recorded speech, make sure you answer them in the correct order to avoid becoming confused or falling behind, especially when attempting selection tasks and tasks that require you to label maps/diagrams.

16. Wait until you are certain of the speaker's full meaning, as speakers sometimes make adjustments to what they have just said.

17. Look for key words in the charts. When you are required to complete tables or figures, focus on their headings to avoid losing track of the speech.

18. Familiarise yourself with and remain alert to the pronunciation of ' $r$ ' in a British accent, which is often omitted if it is not followed by a vowel. Sometimes students mistake an ' $r$ ' for an 'a' as pronounced by an English speaker.

19. Focus on listening, but remain relaxed. If you are distracted for a moment, stay calm and refocus.

20. Keep an open mind about speakers' beliefs and opinions.

21. When answering questions on long passages of recorded speech, try to identify and remember key words and synonyms.

22. Do not focus solely on a speaker's overt meaning; try to identify the emotions and meanings that underlie his/her words.

23. If you are not sure whether you have understood a speaker's meaning, try to decide whether your interpretation makes sense.

24. Identify the speaker's most important ideas by paying special attention to phrases such as 'I mean...', 'I believe...' and 'my point is...'.

25. Decide quickly. As human thought is much faster than speech, you can make up your mind quickly while the tape is playing.

\section{Data Analysis and Results}

The FLLAS and FLSAS, comprising 30 and 21 items respectively, were used with all of the EFL participants. Overall ratings for the items were obtained by measuring the frequency statistics of the participants' ratings. As some of the statements in the FLLAS and FLSAS were negatively phrased, responses to these statements were reversed before being recorded, ensuring that a high score indicated a high level of anxiety for all of the items. The point biserial correlation coefficient (rpb) was calculated to determine the correlation between the students' FL social anxiety and social class. The Pearson correlation coefficient (r) was used to compare the FL social anxiety and FL proficiency of the students who received social-anxiety treatment. The correlation coefficient $\mathbf{r}_{\mathbf{x y}}$ was used to evaluate the correlation between EFL learners' listening test anxiety and listening performance. Listening performance was scored using a version of the 40-question IELTS, with scores out of 40 converted to band scores from 0 to 9 . The data gathered from the open-ended questionnaire were assessed as follows.

\subsection{Results of Open-ended Questionnaire}

The first question asked the students to describe the factors that make them anxious during listening tests. The descriptive statistics shown in Table 1 suggest that the participants' interpretations of their FL listening test anxiety varied according to social class.

Most (13) of the students from sociable social classes reported that they encountered no anxiety-inducing issues during listening tests. However, only four of the participants from unsociable social classes gave the same answer. Only six participants from sociable social classes were anxious about their listening-test marks, compared with nine participants from unsociable sociable classes. Eight students from sociable social classes were worried about falling behind in their test questions, and twelve students from unsociable social classes reported the same anxiety. 
No factors causing anxiety

$13 / 4$

Final mark

Falling behind in the test

$8 / 12$

Teacher's response

$2 / 8$

Competition to hand in answer sheets first
$3 / 2$

The second open-ended question concerned the physiological and psychological changes experienced by students during listening tests. Five EFL learners from unsociable social classes reported no such changes, whereas eight learners from sociable social classes described experiencing certain psychological or physical changes during EFL listening tests. Five participants from sociable social classes and twelve participants from unsociable social classes were afraid to take EFL listening tests. The sociable and unsociable social classes differed most significantly in their responses to the 'happiness' item. Three times as many students from sociable social classes (nine) as unsociable social classes (three) reported feeling happy during listening tests. For more details, refer to Table 2.

Table 2. Physiological and psychological changes during EFL listening tests

Sociable social class/Unsociable social class

$\begin{array}{lc}\text { Sweating } & 4 / 9 \\ \text { Shaking/stomach pain } & 3 / 7 \\ \text { No change } & 8 / 5 \\ \text { Happiness } & 9 / 3 \\ \text { Fear } & 5 / 12\end{array}$

The third open-ended question asked the participants to identify issues that bothered them during EFL listening tests. As illustrated in the descriptive statistics in Table 3, the participants highlighted a wide range of issues. 'Everybody will ignore me' was the most common source of anxiety among the participants from unsociable social classes, of whom 10 gave this answer. However, only four of the participants from sociable social classes reported the same anxiety. Five EFL learners from sociable social backgrounds described their reluctance to be the centre of attention, but this anxiety seemed more prevalent among the students from unsociable social backgrounds, of whom nine gave the same answer. Interestingly, the number of students from unsociable social classes who were afraid of being laughed at for making a mistake (eight) was the same as the number of students who reported that their minds went blank when listening to English.

Table 3. Issues that bother EFL learners during listening tests

\begin{tabular}{ll}
\hline & \multicolumn{1}{c}{ Sociable social class/Unsociable social class } \\
\cline { 2 - 2 } Everybody will ignore me & $4 / 10$ \\
I am afraid of appearing foolish & $3 / 5$ \\
Everybody will laugh at me if I make a mistake & $4 / 8$ \\
My mind goes blank when I listen to English & $3 / 8$ \\
I feel anxious when I am the centre of attention & $5 / 9$ \\
\hline
\end{tabular}

\subsection{Results of FLLAS and FLSAS}

Overall, the students reported the highest anxiety scores for items 4 and 22 of the FLLAS ('I feel intimidated by the task of listening to spoken English' and 'I am afraid of taking English listening comprehension tests'), which received mean scores of 4.03126 and 3.98 respectively. Items 6 and 8 ('I get upset when I hear unfamiliar grammatical forms during an English listening test' and 'It bothers me to encounter words that I can't pronounce when listening to English') elicited the least anxiety, with mean scores of 1.3321 and 1.6. The results for items $12($ mean $=2.4335)$ and $14($ mean $=2.721)$ suggest that the participants who enjoyed listening to English songs or watching/listening to English television or radio programmes felt more confident during English listening tests. 
The participants from unsociable social classes recorded higher anxiety scores for item 12 ('I feel nervous about trying to keep up with people from different social backgrounds') than their counterparts from sociable social classes, with mean anxiety scores of 3.3432 and 2.232, respectively. Whereas most of the EFL learners from unsociable social classes were concerned about taking listening tests due to their different social status (mean $=2.8943)$, only a few of the participants from sociable social classes reported the same anxiety (mean $=1.2312$ ). Similarly, the students from sociable social classes were less concerned about item 21 ('My parents care little about my foreign-language learning, which discourages me from learning English') than the students from unsociable social classes, with mean scores of 1.7865 and 2.8843 , respectively.

With regard to the relationship between social anxiety and social class, the point biserial correlation coefficient for the FLSAS revealed a moderate positive correlation of 0.58 for the FL learners from sociable social classes, and a slightly lower positive correlation of 0.53 for the FL learners from unsociable social classes. The standard deviation indicated that the participants from unsociable social classes experienced more variable anxiety levels than the learners from sociable social classes. Both values were lower than the 0.05 significance level, which suggests that the difference between the social anxiety reported by the participants with sociable social backgrounds (2.33 points) and that reported by the participants with unsociable social backgrounds(3.64 points) (the latter exceeding the former by 1.31 points) was not due to chance variation. Therefore, the first null hypothesis was rejected and the first directional hypothesis approved (Table 4).

Table 4. Point-biserial correlation (rpb) between participants' FL social anxiety and social class

Social anxiety mean score/rpb for social anxiety and social class/significance level/confidence intervals for mean difference in anxiety (lower and upper)

Sociable social class

SD

Unsociable social class

SD
$2.33 / 0.4812 / 0.58 / 0.043 / 1.8,3.8$

0.824

$3.64 / 0.53 / 0.038 / 2.1,4.6$

1.119

According to the results of the FLLAS and FLSAS taken midway through the course, the participants' FL social anxiety and FL listening anxiety levels were 2.8128 and 3.3026 respectively, on a scale from 1 to 5 . After receiving socialanxiety treatment during the last 2 weeks of the course, the participants' social-anxiety level dropped from 2.8128 to 1.5323. Surprisingly, the students' FL listening anxiety also decreased, from 3.3026 to 1.9643 . The Pearson correlation between FL social anxiety and listening anxiety was 0.51 , indicating a moderate positive correlation. The standard deviation revealed that the participants experienced less variable anxiety levels, both in their FL social anxiety levels and FL listening anxiety levels, after their treatment. In both cases, the significance of the reduction was less than 0.05 , which indicates that neither the decrease of 1.2805 points in social-class anxiety nor the decrease of 1.3383 points in listening anxiety after social-anxiety treatment were due to chance variation. In light of these findings, the second null hypothesis was rejected and the second hypothesis confirmed (Table 5).

Table 5. FLLAS and FLSAS results before and after the social-anxiety treatment

\section{Before social-anxiety treatment (In the middle of their term)/After social-anxiety treatment}

\section{FL social anxiety}

$2.8128 / 1.5323$

$S D$

$0.8373 / 0.4811$

\section{FL listening anxiety}

$3.3026 / 1.9643$

$S D$

$1.235 / 0.7823$

Pearson correlation

0.51 
As illustrated in Figure 1, a moderately strong negative Pearson correlation of -0.69 was calculated between the participants' anxiety levels and IELTS listening test scores. A correlation of -0.69 means that each student's listening anxiety predicted approximately 47.61 percent of his/her IELTS listening score, and that the higher the students' listening-anxiety levels, the lower their IELTS listening scores. In light of these results, the third null hypothesis was rejected and the third and final hypothesis confirmed.

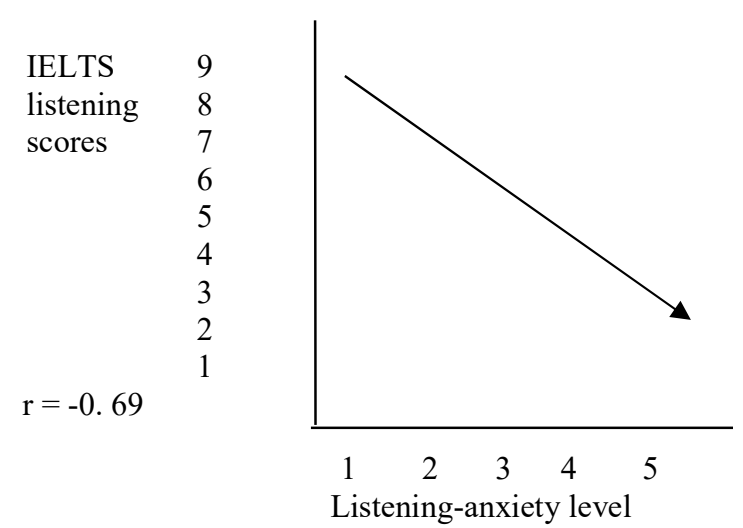

Figure 1. Correlation between IELTS listening scores and listening anxiety

\section{Discussion}

Numerous researchers have emphasised the importance of listening in second-language/FL learning (Ferris, 1998; Field, 2003). As listening comprehension is a central principle of second-language learning, enhancing students' listening skills can significantly improve their overall language proficiency (Vandergrift, 2007). However, the acquisition of listening skills may be impeded by various factors, of which debilitative anxiety is one of the most significant. Chen and Chang (2004) and Pappamihiel (2002) reported that debilitative anxiety has negative effects on students' language learning. The aim of the current research was to increase our understanding of this issue by exploring the relationship between students' social class and their FL social anxiety. The study also investigated the correlation between participants' FL social anxiety and FL listening anxiety, and the effects of FL listening anxiety on EFL learners' listening-test performance.

Compared with issues such as race and ethnicity, social class has received very little attention from language researchers (Block, 2012). Social class is one of the many factors that can impede or enhance students' language learning (Young \& Astarita, 2013). The listening anxiety experienced by some FL learners is associated with underachievement. Listening anxiety may arise from students' awareness of their social class, and is especially severe among students from unsociable social backgrounds. In response to the open-ended questionnaire administered as part of this study, most of the students from sociable social classes identified little or no reason to be anxious during listening tests, whereas many of the students from unsociable social classes highlighted factors that caused listening anxiety. In addition, most of the students from unsociable social classes reported negative attitudes towards listening tests, and were afraid of making mistakes, whereas few of the students from sociable classes experienced these negative responses to listening tests (see Tables 1, 2 and 3). The results also indicated that the social class of FL learners is to some extent related to their level of social anxiety, as students from unsociable social classes were found to be more socially anxious than their peers from sociable social classes.

A fairly significant decrease in the students' social anxiety and FL listening anxiety after social-anxiety treatment was observed. This finding suggests that students' social anxiety and listening anxiety are to some degree related.

Mohammadi Golchi (2012) investigated listening anxiety and its connection with the listening attainment among 63 Iranian IELTS learners. IELTS listening anxiety was found to correlate negatively with students' listening comprehension. Similarly, the results of the current study indicate a moderate negative correlation between these variables; almost 50 per cent of the students' listening scores could be predicted by their listening-anxiety levels (Figure 1)

With regard to ethical considerations, all of the study's participants were aware that they were being observed by their teacher for research purposes. Although IELTS scores are usually given in whole numbers from 1 to 9 , the scores obtained in this study were calculated and recorded to several decimal places to ensure that the differences in the students' scores could be evaluated precisely. The results might have been different if the scores had been calculated in whole numbers, as in the real-life system. In this study, only the listening section of the TOEFL was considered; the reading and writing sections were omitted. Again, the results might have been different if the participants' reading and writing skills had been evaluated. As the relationship between listening and social class is a novel area of research, it was impossible to compare the results of this study with the findings of previous literature. This study may provide a useful foundation for further research to deepen our understanding of the connection between listening and social class. 
In brief, this study offers a critical assessment of the effects of anxiety on the performance of second-language/FL learners. Unlike In'nami (2006), the researcher found a correlation between second language listening anxiety and test anxiety. The results of the study suggest that teachers of FL teachers should aim to address not only students' linguistic problems with listening but problems such as FL listening anxiety, which may relate to students' social background and prevent them from achieving their true language potential. The individuals attitudes can vary in different social contexts (Ling, Hei \& David, 2015). Language instructors should be aware that students from unsociable social backgrounds may experience a certain amount of illogical anxiety that limits their FL listening potential. Instructors should encourage such students to participate more in class and social/group activities to decrease their social anxiety, which is usually based on unrealistic fears. The findings of this study confirm that anxiety is a 'metaphorical' obstacle to learning (Lightbown \& Spada, 2006, p. 37). Therefore, FL teachers who wish to improve their students' listening performance should attempt to decrease their students' anxiety by creating a low-anxiety learning environment and setting low-anxiety tests and helping them cope with second-language or FL challenges.

\section{References}

American Psychiatric Association (2000). Diagnostic and Statistical Manual of Mental Disorders. $4^{\text {th }}$ ed. Washington, DC: American Psychiatric Association Press. Revised text.

Bagheri, M., \& Karami, S. (2014). The effect of explicit teaching of listening strategies and gender on EFL learners' IELTS performance. Journal of Language Teaching and Research, 5, 1387-1392. doi:10.4304/j1tr.5.6.

Block, D. \& Corona, V. (2014) 'Exploring class-based intersectionality'. Language, Culture and Curriculum, 27(1), 27-42.

Barker, C. (1955). Cultural Studies: Theory and Practice. Sage.

Block, D. (2012). Class and SLA: Making connections. Language Teaching Research, 16(2), 189-202.

Brown, H. D. (2007). Principles of Language Learning and Teaching (5 ${ }^{\text {th }}$ edition). White Plains, NY: Pearson.

Brown, D. F. (2009). Social class and status. In Mey, J. (Eds.), Concise encyclopaedia of pragmatics (p. 952). Elsevier. ISBN 978-0-08-096297-9.

Chen, T. Y., \& Chang. G. B. (2004). The relationship between foreign language anxiety and learning difficulties. Foreign Language Annals, 37(2), 279-288.

Darnon, C., Dompnier, B., \& Poortvliet, M. (2012). Achievement goals in educational contexts. A social psychology perspective. Social \& Personality Psychology Compass, 6(10), 760-771.

Draguns, J. G., \& Tanaka-Matsumi, J. (2003). Assessment of psychopathology across and within cultures: Issues and findings. Behavioral and Research Therapy, 41, 755-776.

Elkhafaifi, H. (2005). Listening comprehension and anxiety in the Arabic language classroom. Modern Language Journal, 89(2), 206-220.

Ferris, D. (1998). Students' views of academic aural/oral skills: A comparative needs analysis. TESOL Quarterly, 32, 290-317.

Field, J. (2003). Promoting perception: Lexical segmentation in second language listening. ELT Journal, 57, $326-333$.

Gracia, P. (2015). Parent-child leisure activities and cultural capital in the United Kingdom: The gendered effects of education and social class. Social Science Research, 52, 290-302.

Grant, J. A. (2001). Class, definition of. In Jones, R. J. B. (ed.), Routledge Encyclopaedia of International Political Economy: Entries $A-F$ (p. 161). Taylor \& Francis.

Hussein, E. (2005). Listening comprehension and anxiety in the Arabic language classroom. Modern Language Journal, 89(2), 206-220.

In'nami, Y. (2006). The effects of test anxiety on listening test performance. System,34(4), 317-340.

Jury, M., Smeding, A., Court, M., \& Darnon, C. (2015). When first-generation students succeed at university: On the link between social class, academic performance, and performance-avoidance goals. Contemporary Educational Psychology, 41, 25-36.

Ling, W. N., Hei, K. C., \& David, M. K. (2015). The perceived value of silence and spoken words in Malaysian interactions. SEARCH: The Journal of the South East Asia Research Centre, 7, 53-70.

Lightbown, P. M., \& Spada, N. (2006). How Languages Are Learned. Oxford: Oxford University Press.

MacIntyre, P. D. \& Gardner, R. C. (1994). The subtle effects of language anxiety on cognitive processing in the second language. Language Learning, 44, 283-305. doi: 10.1111/j.1467-1770.1994.tb01103.x.

Macionis, J., \& Gerber, L. (2010). Sociology (7th ed.), Pearson Education Canada.

Mare, R., D. (2014). Multigenerational aspects of social stratification: Issues for further research. Research in Social Stratification and Mobility, 35, 121-128. 
Mills, N., Pajares, F., \& Herron, C. (2006). A reevaluation of the role of anxiety: Self-efficacy, anxiety, and their relation to reading and listening proficiency. Foreign Language Annals, 39, 276-295.

Mohammadi Golchi, M. (2012). Listening anxiety and its relationship with listening strategy use and listening comprehension among Iranian IELTS learners. International Journal of English Linguistics, 2(4), 115-128.

Phillips, E. M. (1992). The effects of language anxiety on students' oral test performance and attitudes. Modern Language Journal, 76, 14-26.

Price, M. L. (1991). The subjective experience of foreign language anxiety: 19 interviews with highly anxious students. In E. K. Horwitz and D. J. Young (eds), Language Anxiety: From Theory and Research to Classroom Implications (pp. 101-108). Upper Saddle River, NJ: Prentice Hall, Inc.

Putwain, D. W. (2008). Deconstructing test anxiety. Emotional and Behavioural Difficulties, 13, 141-155.

Vandergrift, L., (2007). Recent developments in second and foreign language listening comprehension research. Language Teaching, 40, 192-209.

Young, D. J. (1986). The relationship between anxiety and foreign language oral proficiency ratings. Foreign Language Annals, 19, 439-445.

Young, D. J. (1999). A perspective on foreign language learning: From body to mind to emotions. In D. J. Young (ed.), Affect in Foreign Language and Second Language Learning: A Practical Guide to Creating a Low-anxiety Classroom Atmosphere (pp. 13-23). Boston: McGraw-Hill.

Young, R. F., \& Astarita, A. C. (2013). Practice theory in language learning. Journal of Language Learning, 172-185.

\section{Appendix A}

FLLAS

The following statements are related to the experience of FL listening anxiety. There are no right or wrong answers. Please rate your personal responses to the statements according to your level of agreement or disagreement with each statement, as follows.

1. Strongly disagree. 2. Disagree. 3. No strong feelings either way. 4. Agree. 5. Strongly agree.

1. I become upset when I am unsure whether I have correctly understood spoken English.

2. When I listen to English, I often understand the words but still cannot quite understand what the speaker is saying.

3. When taking an English listening test, I often become so confused that I cannot remember what I have heard.

4. I feel intimidated by the task of listening to spoken English.

5. I become nervous when I am unfamiliar with the topic of spoken English during a listening test.

6. I get upset when I hear unfamiliar grammatical forms during an English listening test.

7. I become nervous and confused when I don't understand every word spoken in an English listening test.

8. It bothers me to encounter words that I can't pronounce when listening to English.

9. I usually translate words in their exact order to identify what is being said in English on the tape.

10. By the time I have got past the strange sounds in English, it is difficult to remember what I am listening to.

11. I am worried about all of the new phonological rules that must be learned to understand spoken English.

12. I enjoy listening to English songs and watching/listening to English television or radio programmes.

13. I feel confident when taking English listening tests.

14. Now that I am used to listening to spoken English, English listening tests are not very difficult.

15. The hardest part of learning English is understanding spoken English.

16. I am more confident in my ability to understand written English than spoken English.

17. I don't mind listening to English by myself, but I feel very uncomfortable when I have to listen to English as part of a group.

18. I am satisfied with the level of listening comprehension in English that I have achieved so far.

19. I become anxious if I am not familiar with the relevant cultural background when taking an English listening test.

20. I would feel more relaxed about taking listening tests if I had a full understanding of English history and culture.

21. I worry about failing English listening comprehension tests.

22. I am afraid of taking English listening comprehension tests.

23. Listening to native English speakers makes me feel uneasy and confused.

24. I almost never become uptight during English listening comprehension tests.

25. I become nervous when taking English listening comprehension exams.

26. I experience a sinking feeling when I think about trying to complete a difficult listening-comprehension exercise.

27. My mind goes blank and I am unable to think clearly when my instructor asks me a question in English.

28. I feel particularly nervous about English listening comprehension exercises when I know that they will be graded.

29. I feel more relaxed when clear instructions are provided before English listening comprehension tests begin.

30. I answer some questions too quickly and thus incorrectly because I do not have enough time to think about what has been said to me.

Note. The scale used in this study is an adapted version of the FLLAS, developed by Elkhafaifi (2005) in 'Listening comprehension and anxiety in the Arabic language classroom', Modern Language Journal, 89(2), 206-220. Copyright (C) 2010 American

Psychological Association. Adapted with permission. 


\section{FLSAS}

The following statements are related to the experience of FL social anxiety. There are no right or wrong answers. Please rate your personal responses to the statements according to your degree of agreement or disagreement with each statement.

1. Strongly disagree. 2. Disagree. 3. No strong feelings either way. 4. Agree. 5. Strongly agree.

1. Making eye contact while speaking a foreign language makes me uncomfortable.

2. I do not feel comfortable when taking listening tests because my social status is different from that of my classmates.

3. Calling someone by their name makes me uncomfortable.

4. Participating in a small-group activity with people from different social backgrounds bothers me.

5. Speaking in public bothers me.

6. The possibility of being regarded with contempt by others bothers me.

7. Talking to the teacher annoys me.

8. Acting or performing in front of others bothers me.

9. Greeting someone in a social context makes me uncomfortable.

10. It bothers me to be observed while doing a task.

11. It bothers me to be observed by others while taking a listening test.

12. I feel nervous about trying to keep up with people from different social backgrounds.

13. Listening to someone whom I do not know very well makes me uncomfortable.

14. Seeing strangers makes me uncomfortable.

15. It is annoying to arrive at the room in which the test will be held to find others already seated.

16. Speaking up during a test makes me anxious.

17. Taking a test with my peers distracts me.

18. I feel nervous about disagreeing with someone whom I do not know very well.

19. I am afraid of being teased by others for getting a bad grade in a foreign language listening test.

20. I am afraid of being the only one in my class to make a mistake in a foreign-language test.

21. My parents care little about my foreign-language learning, which discourages me from learning English.

\section{Appendix C}

\section{Open-ended Questionnaire}

1. Name the factors, if any, that make you anxious during FL listening tests.

2. What kinds of physiological changes (e.g., shaking, sweating, headache, stomach pain) or psychological changes (e.g., sadness, depression, fear, happiness), if any, do you undergo during listening tests?

3. Does anything bother you during listening tests? If so, please explain why. 